\title{
Causes of low tetanus toxoid vaccination coverage in pregnant women in Lahore district, Pakistan
}

S. Hasnain ${ }^{1}$ and N.H. Sheikh ${ }^{1}$

$$
\begin{aligned}
& \text { أسباب تُدِّي التغطية بتطعيم الحمو امل بلقاح ذيفان الكزاز في مقاطعة لاهور في باكستان }
\end{aligned}
$$

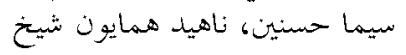

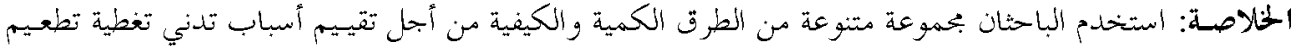

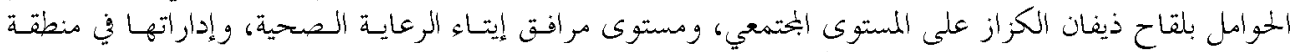

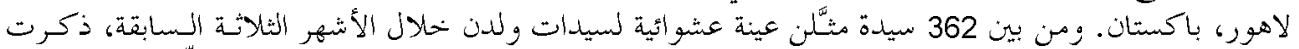

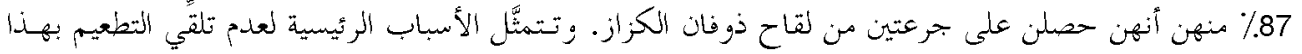

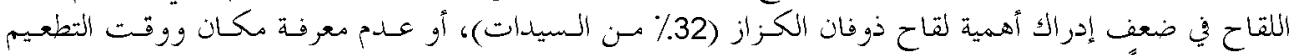

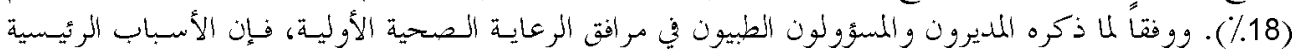

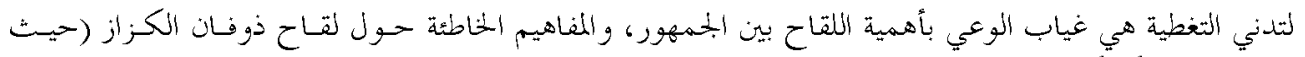

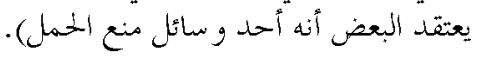

ABSTRACT To assess the causes of low tetanus toxoid (TT) vaccination coverage in pregnant women a mixture of quantitative and qualitative methods were adopted at the community, primary health care delivery and management levels in Lahore district, Pakistan. Out of a random sample of 362 women who had delivered during the previous 3 months, $87 \%$ recalled receiving 2 doses of TT. The main reasons for non-vaccination were poor knowledge about the importance of TT (32\% of women) or the place and time to get vaccinated (18\%). According to the managers and primary health care medical officers, the main reasons for low coverage were lack of awareness about the importance of vaccination among the public and misconceptions about TT vaccination (e.g. that it was a contraceptive).

Causes de la faiblesse de la couverture vaccinale antitétanique chez la femme enceinte dans le district de Lahore au Pakistan

RÉSUMÉ Afin d'évaluer les causes de la faiblesse de la couverture vaccinale antitétanique chez la femme enceinte, il a été fait appel à un assemblage de méthodes quantitatives et qualitatives aux niveaux de la collectivité, de la prestation des soins de santé primaires et de l'administration des programmes dans le district de Lahore au Pakistan. Sur un échantillon aléatoire de 362 femmes ayant accouché dans les 3 mois précédents, $87 \%$ se sont souvenues avoir reçu 2 doses de vaccin antitétanique. Les principales raisons de cette absence de vaccination sont une méconnaissance de l'importance du vaccin antitétanique (32\% des enquêtées) ou du lieu et du moment auxquels se faire vacciner (18\%). Selon les administrateurs de programme et les médecins de soins de santé primaires, les principales causes de la faiblesse de cette couverture sont la non-prise de conscience par le public du rôle crucial de la vaccination et la mésinformation avec des idées préconçues prêtant par exemple une action contraceptive au vaccin antitétanique.

${ }^{1}$ Department of Community Medicine, Allama Iqbal Medical College, Lahore, Pakistan (Correspondence to S. Hasnain: drseemahasnain@yahoo.com).

Received: 09/08/05; accepted: 31/10/05 


\section{Introduction}

Tetanus is a vaccine-preventable disease that causes an annual total of 309000 deaths [1]. Of particular concern is maternal and neonatal tetanus (MNT) which represents a triple failure of public health in terms of routine vaccinations, antenatal care and clean delivery/umbilical cord care services. MNT is a swift and painful killer that killed about 200000 newborns in year 2000 [2]. The goal of MNT elimination was declared jointly by the United Nations Children's Fund (UNICEF), the World Health Organization (WHO) and the United Nations Population Fund (UNFPA) along with the establishment of a global fund for MNT elimination.

MNT elimination is defined as the achievement of less than 1 case of neonatal tetanus per 1000 live births annually in every district of a country in the world. The 3 key strategies for achieving MNT elimination recommended by WHO/UNICEF/UNFPA are: provision of at least 2 doses of tetanus toxoid (TT2) to all pregnant women in high risk areas and 3 doses (TT3) to all women of childbearing age; promotion of clean delivery services to all pregnant women and ensuring effective surveillance for MNT.

There is a renewed momentum to achieve MNT elimination in the 57 countries which have not yet done so. However, $90 \%$ of the neonatal deaths occur in 27 of the 57 countries [2]. Pakistan is one of the 8 highburden countries which account for about $73 \%$ of neonatal tetanus deaths. These include Bangladesh, China, the Democratic Republic of the Congo, Ethiopia, India, Nigeria, Pakistan and Somalia [3]. In Pakistan, 22000 neonatal deaths occur every year due to MNT [4].

In most developing countries maternal TT vaccination is implemented as part of the routine vaccination programme or implemented as a supplemental activity. However, large areas remain underserved due to logistic, cultural, economic or other reasons. The 57 countries were ranked in June 2000 into A, B and C classes. Class C countries need 3-4 years to phase in elimination activities [4]. Pakistan is included in class $\mathrm{C}$ as more than $50 \%$ of the districts are at high risk for MNT because of the limited health infrastructure which is indicated by $50 \%$ or lower coverage of the third dose of diphtheria/pertussis/tetanus (DPT3), and serious manpower and logistic constraints. There are extremely wide variations in TT vaccination coverage from district to district in Pakistan even when they are in close proximity. The delivery and acceptance of recommended vaccinations is an ongoing challenge for health care providers and health care and public health systems. Reducing the burden of immunizable diseases is thus an important aspect of human capital development and a critical investment in the future of the country. The information system of the Expanded Programme of Immunization (EPI) is reporting around $80 \%$ of the coverage of children and about 38\% of the TT2 coverage of pregnant mothers in the province of Punjab [5].

There are also variations in TT coverage even across the provinces of Pakistan. In a study conducted in Peshawar district of North West Frontier Province of Pakistan, $65 \%$ of women in urban areas were vaccinated, while in rural areas $60 \%$ were vaccinated. Females in the urban area were older and had more knowledge regarding TT vaccination than females in the rural areas. More women in the urban areas had made antenatal care visits $(79 \%)$ than those in rural area (50\%) [6].

Despite considerable resources being invested into the routine EPI programme in Pakistan, there is no or very slow improvement in the TT coverage among the 
pregnant women with the supplementary immunization activities. The routine reporting system of EPI is supplemented by the coverage evaluation survey, the focus of which is basically only on coverage. Little or no research has been done to analyse the causes of low TT coverage of pregnant women $\mathrm{n}$ Pakistan. The present study therefore focused on assessing the different causes of low vaccination coverage of TT2 in pregnant women in Lahore district in order to suggest ways of improving routine vaccination coverage towards helping to eliminate neonatal tetanus.

\section{Methods}

\section{Study design and setting}

This was a cross-sectional study in Lahore district, in 4 parts: (1) a household interview survey with married women who had recently delivered; (2) focus group discussions (FGD) with married women of childbearing age, husbands and health workers; (3) individual interviews with primary health care (PHC) centre medical officers; and (4) individual interviews with managers of the EPI. Lahore is the provincial capital with a total population of 6318475 . The majority of the population is urban based, with only $17.6 \%$ living in rural areas [7]. Lahore district is administratively divided into 6 towns having 150 union councils. The study definition of adequate vaccination was when a woman had received the second dose of TT (TT2).

\section{Instruments and staff}

Four sets of questionnaires were developed: (1) household survey form; (2) FGD guidelines; (3) PHC centre survey instrument; and (4) questionnaire for individual interviews of managers.

We selected 3 teams of researchers, each having 2 members: 2 teams were allocated
17 union councils for the household survey and the 3rd team was allocated 18 union councils. These teams were also directed to interview the medical officer in charge of PHCs if they worked within their union councils. Training of data collectors for delivering the household and PHC questionnaires was followed by field testing of questionnaires. Only female interviewers specially trained for this purpose carried out the household interviews with women.

\section{Household survey of newly- delivered women \\ Sample}

A representative sample of 362 married women was randomly selected for household interviews. The criteria used for sample estimation was the population size of the district, the reported prevalence of TT coverage and $\pm 5 \%$ worst expectable results. The eligibility criteria were married women of child-bearing age (15-49 years) who had delivered during the past 3 months between 17 October 2003 to 17 January 2004 after 28 weeks of gestation.

A multi-stage stratified random sampling technique was used for the identification of the households. Lahore district was divided into 6 strata according to the administrative division of towns. At the 1st stage of the sampling, 35\% of the union councils (total 52) from each town were selected using a random number list from Epi-Info, version 6.0 statistical package. During the 2 nd stage of sampling, a list of all villages/wards from the selected union councils during the first stage was drawn up. Out of this list 1 village/ward was selected randomly from each union council using a random number list. During the 3rd stage, from each village/ ward selected, a cluster of 7 households was selected randomly, except for 1 village where 5 respondents were interviewed. To select each household, the researcher stood 
at a central location in the cluster, e.g. the largest mosque or school, and rotated a pencil; the direction of the sharpened end indicated the 1 st household to be visited. The 2nd household was the one nearest to the first. The 3 rd household was the one whose front door was closest to the front door of the household just visited (i.e. on either side of the street). This was repeated until the required number of women had been interviewed in the cluster.

\section{Data collection}

The questionnaire was divided into $5 \mathrm{sec}-$ tions to collect information on the following topics: social, demographic and economic characteristics of the woman; information about her last pregnancy; her knowledge about TT vaccination and the reasons for non-vaccination. The questions were closed-ended with possible options listed against each and coded. The interviewers chose answers from the given options but if not listed, the response was recorded as "other" with specific information. The women's responses were checked from their vaccination card which is a client-retained record. At the start of interview the purpose of the survey was explained to the interviewees and informed verbal consent was taken. The interviewees were assured about the confidentiality of their identity.

\section{FGDs with women, husbands and health workers \\ Sample}

Each FGD contained 5-10 participants from the local community, comprising married women of child-bearing age, husbands of the women, the local community health workers known as lady health workers (LHW), traditional birth attendants and a vaccinator from the area. The staff of the PHC centres helped in the selection of the participants, except for the women and their spouses. All couples present in the health centre at the start of FGD were included; women are usually accompanied by their husbands when visiting to the PHC. The timing of FGDs was selected to be convenient for the health care providers, i.e. at non-peak hours.

\section{Data collection}

These discussions were conducted by a social scientist accompanied by a medical doctor who recorded the proceedings. A total of 6 FGDs were conducted, 1 in each town, within the health centre premises. At the start of the discussion, the participants were told about the objectives of holding the FGD and value of their views about TT vaccination. The participants were told about the importance of their suggestions for improving TT vaccination coverage. The moderator started the discussion using guidelines prepared in advance. The discussion revolved around knowledge about tetanus and its vaccination, reasons for not getting the vaccination and suggestions for improvement of vaccination coverage. The information collected was analysed by a social scientist using the standardized analytical methods for qualitative data. The responses were analysed by type of respondent.

\section{Interviews with medical officers in charge of PHC centres \\ Sample}

All the PHC facilities which fell within the selected union councils were surveyed. In the urban areas no PHC centre existed, but in rural areas, every union council has 1 PHC centre. There were 10 PHC centres in the selected union councils so 10 medical officers in charge were interviewed. The medical officer in charge is a medical doctor who is responsible for providing medical 
care and management of a particular health facility.

\section{Data collection}

The interview was designed to gauge medical doctors' opinions about the reasons for low TT coverage at service delivery points. The following aspects of each PHC centres were explored with an open-ended questionnaire: catchment area population; geographic accessibility; availability of staff relevant to EPI vaccination; links with the outreach vaccination teams; vaccination services at static centre; opinion about reasons for low coverage of TT vaccination; and suggestions for the improvement of the TT coverage of pregnant women.

\section{Interviews with EPI managers Sample}

Interviews were made with 5 key people who were directly responsible for EPI activities in the district: the executive district health officer, district health officer, deputy district health officer, district superintendent of vaccination, and an inspector of vaccination.

\section{Data collection}

An open-ended questionnaire was used for this purpose. The interview was conducted by a medical doctor. The main focus of the interview was on exploring reasons for low TT coverage and suggestions for improvement.

\section{Statistical analysis}

The data from household surveys was checked manually, entered into SPSS and screened for coding errors. SPSS was used to calculate rates, proportions of coverage and confidence intervals (CI). Contingency data tables were analysed with the chi-squared test. $P<0.05$ was considered statistically significant. The analysis of the qualitative data was done manually by a social scientist.

\section{Results}

\section{TT coverage}

Of the 362 women responding to the household survey, $314(87 \%)$ reported receiving at least TT2 vaccination, but this percentage decreased with TT3 and onwards (Table 1). Most (99\%) of the respondents who claimed to have TT vaccination, could not produce the record card. Out of those who received TT2, 263 (84\%) had some level of education, with only $16 \%$ completely uneducated. There was a significant association between vaccination status and educational level as well as attending antenatal care (yes/no) and number of antenatal care visits. The TT2 coverage increased with the level of education. About $45 \%$ of respondents with matriculation educational level or above had had TT2 $(P<0.0001)$ (Table 2$)$. The TT2 coverage was greater among the respondents who had had antenatal care as compared to those who did not (Table 2). Respondents with $3+$ antenatal visits had greater TT2 coverage than those with $<3$ visits (Table 2).

\begin{tabular}{|c|c|c|c|c|c|c|}
\hline \multicolumn{7}{|c|}{$\begin{array}{l}\text { Table } 1 \text { Tetanus toxoid (TT) vaccination } \\
\text { coverage for women interviewed in the } \\
\text { household survey (by reported history or } \\
\text { card) }\end{array}$} \\
\hline \multirow{3}{*}{$\begin{array}{l}\text { No. of T1 } \\
\text { doses }\end{array}$} & \multicolumn{6}{|c|}{ TT vaccination received } \\
\hline & \multicolumn{2}{|c|}{ No } & \multicolumn{2}{|c|}{ Yes } & \multicolumn{2}{|c|}{ Total } \\
\hline & No. & $\%$ & No. & $\%$ & No. & $\%$ \\
\hline TT1 & 34 & 9 & 328 & 91 & 362 & 100 \\
\hline TT2 & 48 & 13 & 314 & 87 & 362 & 100 \\
\hline TT3 & 159 & 44 & 203 & 56 & 362 & 100 \\
\hline TT4 & 243 & 67 & 119 & 33 & 362 & 100 \\
\hline TT5 & 300 & 83 & 62 & 17 & 362 & 100 \\
\hline
\end{tabular}




\begin{tabular}{|c|c|c|c|c|c|c|}
\hline \multirow[t]{3}{*}{ Variable } & \multicolumn{6}{|c|}{ TT2 vaccination received } \\
\hline & \multicolumn{2}{|c|}{ No } & \multicolumn{2}{|c|}{ Yes } & \multicolumn{2}{|c|}{ Total } \\
\hline & No. & $\%$ & No. & $\%$ & No. & $\%$ \\
\hline \multicolumn{7}{|l|}{ Mother's educational level } \\
\hline Uneducated & 27 & 35 & 51 & 65 & 78 & 100 \\
\hline Non-formal education & 4 & 11 & 31 & 89 & 35 & 100 \\
\hline Primary & 2 & 8 & 23 & 92 & 25 & 100 \\
\hline Middle & 6 & 8 & 67 & 92 & 73 & 100 \\
\hline Matriculation & 5 & 6 & 75 & 94 & 80 & 100 \\
\hline Above matriculation & 4 & 6 & 67 & 94 & 71 & 100 \\
\hline \multirow[t]{2}{*}{ Total } & 48 & 13 & 314 & 87 & 362 & 100 \\
\hline & \multicolumn{6}{|c|}{$\chi^{2}=40.00, P<0.0001$} \\
\hline \multicolumn{7}{|l|}{$\begin{array}{l}\text { Antenatal care in last } \\
\text { pregnancy }\end{array}$} \\
\hline Yes & 25 & 52 & 281 & 89 & 306 & 85 \\
\hline No & 23 & 48 & 33 & 11 & 56 & 15 \\
\hline \multirow[t]{2}{*}{ Total } & 48 & 100 & 314 & 100 & 362 & 100 \\
\hline & \multicolumn{6}{|c|}{$\chi^{2}=44.55, P<0.0001$} \\
\hline \multicolumn{7}{|l|}{ No. of antenatal visits } \\
\hline 0 & 23 & 41 & 33 & 59 & 56 & 100 \\
\hline$<3$ & 10 & 16 & 52 & 84 & 62 & 100 \\
\hline$\geq 3$ & 15 & 6 & 229 & 94 & 244 & 100 \\
\hline \multirow[t]{2}{*}{ Total } & 48 & 13 & 314 & 87 & 362 & 100 \\
\hline & \multicolumn{6}{|c|}{$\chi^{2}=48.84, P<0.0001$} \\
\hline
\end{tabular}

\section{Reasons for low TT coverage \\ Household survey}

When asked about the reasons for not having TT vaccination, the women's responses varied widely. The most common reason $(32 \%)$ was that the women did not know the importance of the TT vaccination, followed by $18 \%$ who did not know the correct place or time to get the vaccination. Other reasons are listed in Table 3.

Focus group discussions

In the FGDs most women confessed that they did not know about TT and its dangerous outcome. A few women had only heard about its signs and symptoms from other women and believed that these signs were due to evil look of devils, jinn and other evil creatures.

More than $90 \%$ of women mentioned that vaccinators and other workers had not visited their houses and never asked for or given any information about TT, nor had they offered any services. LHWs discussed vaccinations against tetanus for the children but not for the women. All the women said that if they had been informed about TT by the LHWs then they would have been vaccinated. A small number of women interviewed (about 10\%) mentioned that they were informed about TT by LHWs and got vaccinated from adjacent health facilities. 


\begin{tabular}{|c|c|c|}
\hline Reasons & $\begin{array}{c}\text { No. of } \\
\text { respondents }\end{array}$ & $\%$ \\
\hline $\begin{array}{l}\text { Don't know about the } \\
\text { importance of TT }\end{array}$ & 16 & 32 \\
\hline $\begin{array}{l}\text { Don't know about place \& time } \\
\text { for getting TT }\end{array}$ & 9 & 18 \\
\hline $\begin{array}{l}\text { Scared of injections \& side- } \\
\text { effects }\end{array}$ & 4 & 8 \\
\hline Vaccination team did not visit & 3 & 6 \\
\hline $\begin{array}{l}\text { Thought TT injections are for } \\
\text { family planning }\end{array}$ & 3 & 6 \\
\hline $\begin{array}{l}\text { Not allowed by husband/ } \\
\text { mother-in-law }\end{array}$ & 2 & 4 \\
\hline No time & 1 & 2 \\
\hline Health centre/hospital far away & 1 & 2 \\
\hline $\begin{array}{l}\text { Vaccinator not available at the } \\
\text { time of visit to government } \\
\text { facility }\end{array}$ & 1 & 2 \\
\hline Don't believe in TT & 1 & 2 \\
\hline Don't know & 9 & 18 \\
\hline Total & 48 & 100 \\
\hline
\end{tabular}

A few women mentioned that they did not have time to get vaccinated due to the burden of work in the house and a few women also mentioned that they made many visits at nearby health facilities but nobody was present there to vaccinate them.

Some of the women showed apprehension about TT being a contraceptive injection. A few women said that mother-in-laws were a barrier to getting vaccinated due to jealousy or desire to control daughter-inlaws. Older women consider vaccination of no value because they had experience of giving birth to children without TT vaccination and did not face a problem.

\section{PHC centre medical officers}

The main reasons given for low TT coverage by the 10 medical officers in charge of the PHC facilities were lack of awareness regarding TT vaccination among the public, misconceptions/misbeliefs about TT injection (e.g. that they cause abortions or infertility, or that they are used for family planning, etc.) and behaviour of mother-inlaws and husbands. Other reasons are listed in Table 4.

\section{EPI managers}

The most common reasons for low coverage identified by the 5 EPI managers were lack of awareness among the public regarding

\begin{tabular}{l}
$\begin{array}{l}\text { Table } 4 \text { Reasons for low tetanus toxoid } \\
\text { vaccination (TT) coverage as stated by } 10 \\
\text { medical officers in charge of primary health } \\
\text { care facilities in Lahore district }\end{array}$ \\
\hline $\begin{array}{l}\text { Reasons } \\
\text { respondents }\end{array}$ \\
$\begin{array}{l}\text { Lack of awareness about TT } \\
\text { among public }\end{array}$ \\
$\begin{array}{l}\text { Misconceptions about TT among } \\
\text { public }\end{array}$ \\
$\begin{array}{l}\text { Behaviour of husbands \& } \\
\text { mothers-in-law }\end{array}$ \\
$\begin{array}{l}\text { Low literacy rate in community } \\
\text { Lack of interest of field workers }\end{array}$ \\
$\begin{array}{l}\text { Refrigerator/cold chain facility not } \\
\text { available }\end{array}$ \\
$\begin{array}{l}\text { Vacant posts among vaccination } \\
\text { staff }\end{array}$ \\
$\begin{array}{l}\text { Under-reporting/lack of } \\
\text { documentation by the health } \\
\text { providers }\end{array}$ \\
$\begin{array}{l}\text { Non-availability of TT vaccination } \\
\text { daily }\end{array}$ \\
$\begin{array}{l}\text { Side-effects of TT vaccination } \\
\text { a }\end{array}$ \\
\hline
\end{tabular}

${ }^{a}$ For example, pain, swelling or abscess formation due to faulty techniques. 
TT coverage and misconceptions/misbeliefs about TT injections. Other reasons are listed in Table 5.

\section{Discussion}

The study was undertaken to evaluate the TT coverage in the Lahore district of Pakistan and to understand the reasons for low coverage at various levels. We examined the TT coverage (from history and card) among 362 mothers who had delivered within the previous 3 months. Although TT2 coverage among these mothers was

\begin{tabular}{|c|c|}
\hline Reason & $\begin{array}{c}\text { No. of } \\
\text { respondents }\end{array}$ \\
\hline $\begin{array}{l}\text { Lack of awareness about TT } \\
\text { among public }\end{array}$ & 5 \\
\hline $\begin{array}{l}\text { Misconceptions about TT amons } \\
\text { public }\end{array}$ & 4 \\
\hline $\begin{array}{l}\text { Under-reporting/lack of } \\
\text { documentation by health } \\
\text { providers }\end{array}$ & 2 \\
\hline $\begin{array}{l}\text { Shortage of trained staff at some } \\
\text { facilities }\end{array}$ & 2 \\
\hline $\begin{array}{l}\text { Field staff involved in other } \\
\text { activities }\end{array}$ & 2 \\
\hline $\begin{array}{l}\text { Poor attitude and lack of } \\
\text { commitment by health care } \\
\text { workers }\end{array}$ & 2 \\
\hline $\begin{array}{l}\text { Misguidance of the public by } \\
\text { quacks, religious leaders \& } \\
\text { traditional healers }\end{array}$ & 2 \\
\hline Low literacy rate in community & 2 \\
\hline $\begin{array}{l}\text { Poor socioeconomic status of } \\
\text { community }\end{array}$ & 1 \\
\hline Side-effects of TT vaccinationa & 1 \\
\hline
\end{tabular}

aFor example, pain, swelling or abscess formation due to faulty techniques. relatively high (87\%), and is much higher than the provincial coverage $(62 \%)$ [8], only $17 \%$ of women achieved a complete series of 5 injections, which is well below the WHO expected level of vaccination of $100 \%$ of the pregnant women [4]. Attempts should continue to increase the coverage with special focus on the causes of low coverage.

In this study, attendance at antenatal care had a very strong effect on TT2 coverage. TT vaccination is one of the important components of antenatal care and an increase in antenatal visits by the pregnant women significantly increased the TT coverage.

The TT2 coverage in the present study $(87 \%)$ is higher than the third party evaluation conducted in 2003 which reported $80 \%$ TT2 coverage (from history and card) in Lahore district [8]. The most probable explanation of this difference of coverage could be the different methodology and respondents. In the third party evaluation the respondents were mothers having children $0-11$ months of age and 30 clusters were selected randomly, whereas in the present study the respondents were mothers in the same age group who had delivered during the previous 3 months and multistage random sampling technique was used to identify 52 clusters. Only $1 \%$ of the mothers could produce the vaccination card as compared to $3 \%$ in the third party evaluation [8]. The most probable reason for this difference could be logistical-the interrupted and irregular supply of printed materials and vaccination cards.

The reliability of women's recall of their TT status can be questioned. However, pregnancy and childbearing are special events to the mother and she can be expected to recall important events related to each pregnancy. This is supported by a study in the Central African Republic, a country facing major public health challenges and resource con- 
straints, part of the multiple indicator cluster survey. Among 222 mothers, weighted TT coverage based on mother's recall was $74.4 \%$ and tetanus antitoxin seroprevalence was $88.7 \%$ [2]. In another study conducted in Matlab, rural Bangladesh, women's recollection of TT vaccination was compared with carefully maintained records of TT dose and found to be good, but considerably reduced if they had received more than 2 doses. Recollection was also reduced if the dose was administered more than a year before questioning. Younger women, with fewer children and with good vaccination status, tended to have a better recollection of the number of doses received. These results suggest that maternal recall may underestimate TT doses received a year before the date of questioning [9].

The most common reason $(32 \%)$ for inadequate TT vaccination reported by the women was that they were not aware of the importance of TT vaccination and did not know where and when to get the vaccination $(18 \%)$. It is interesting to note that $6 \%$ of the respondents thought that these injections had something to do with contraception because these are provided by the government free of charge. During the focus group discussions with local communities almost the same reasons for low TT coverage were mentioned as in the household survey.

If a proper awareness campaign using all the available channels were launched, supported by a strengthening of the vaccination delivery system, it might be possible to achieve $100 \%$ TT2 coverage of pregnant mothers. However, the underlying causes of low coverage-such as lack of decision-making power of women, low women's literacy rate and poor attendance at antenatal care-need to be addressed in addition to the factors significantly associated with vaccination coverage-such as education and antenatal care services as shown by this study and other studies in Asia and elsewhere. In a study at a hospital in Ankara, Turkey, the vaccinated women $(18.9 \%$ with at least 1 dose of TT) were younger, of lower parity and had attended more antenatal care visits than the unvaccinated women [10]. In another study conducted in Indonesia, mothers who had heard of TT were 1.54 times more likely to have been immunized than those who did not, while mothers who knew the reason for TT were 2.15 times more likely to have been immunized than those who did not, and those who knew at least 1 of the tetanus symptoms were 1.86 times more likely to have been immunized than those who did not, respectively controlling for other variables. Furthermore, women who had antenatal care were 30 times more likely to have been immunized than those who did not. Enhancing mothers' knowledge on tetanus is important to increase the coverage of TT [11]. Likewise, in a study conducted in rural Bihar, India, it was concluded that the likelihood of a pregnant women receiving 2 doses of TT vaccine was affected by factors such as birth order, maternal education, prenatal care provider, household standard of living, health care seeking decision-maker and service availability [12].

The individual interviews with people responsible for management of the vaccination delivery system and in charge of PHC facilities also showed that lack of awareness in the community was the single most important reason for low TT coverage, in addition to other issues related with management and service delivery such as de-motivated health workers and vacant posts of the vaccination staff.. These issues also need to be addressed, not only to achieve $100 \%$ TT2 coverage of the pregnant women but also to improve the vaccination coverage of other vaccine-preventable diseases. 


\section{Conclusions}

It is encouraging that $87 \%$ of the women interviewed were protected against tetanus in Lahore district which is the capital of the province and is the focus of all health activities. However, $13 \%$ of women remained unprotected against tetanus. The situation of TT2 coverage in other parts of the province is likely to be worse than the capital district. The major reasons for nonvaccination were lack of awareness among the community, demotivated health workers and vacant posts of the vaccination staff. The deep-rooted causes are likely to include low literacy levels and low women's empowerment. To achieve the $100 \%$ target of TT coverage, both short-term and long-term interventions are needed.

\section{Recommendations}

- Use a mass media campaign to create awareness among women, their husbands and families about the importance of TT vaccination and the consequences of not being vaccinated.

- Create incentives for outreach workers to boost their morale.

- Train health care providers in interpersonal communication.

- Improve the monitoring and supervision of vaccination activities.
- Provide the equipment required for delivery of vaccination services to all PHCs.

- Ensure that vacant positions for vaccination staff are filled.

\section{Acknowledgements}

The authors express their sincere thanks to all the team members of the Department of Community Medicine, especially Professor Shaheena Manzoor, Head of Department, for invaluable help and encouragement during this study. We also thank Professor Sibit-ul-Hasnain, Principal of Allama Iqbal Medical College, for providing time assistance and cooperation. We are also very thankful to the district administration and the communities for their cooperation during the conduction of the survey. Special thanks to Dr Ayesha Humayun and Dr Mahanaz Anjum Qazi who assisted us in all the phases of field work.

This investigation received technical and financial support from the joint WHO Eastern Mediterranean Region (EMRO), Division of Communicable Diseases (DCD) and the WHO Special Program for Research and Training in Tropical Diseases (TDR): the EMRO DCD/TDR Small Grants Scheme for Operational Research in Tropical and Communicable Diseases.

\section{References}

1. Vandelaer $\mathrm{J}$ et al. Tetanus in developing countries: an update on the Maternal and Neonatal Tetanus Elimination Initiative. Vaccine, 2003, 21(24):3442-5.

2. Deming MS et al. Tetanus toxoid coverage as an indicator of serological protection against neonatal tetanus. Bulletin of the World Health Organization, 2002, 80(9):696-703.
3. Eliminate maternal and neonatal tetanus (MNT) by 2005 [online news] (http://www. medicalnewstoday.com/medicalnews. php?newsid=12383, accessed 9 March 2007).

4. Maternal and neonatal tetanus elimination by 2005. Strategies for achieving and maintaining elimination. Geneva, WHO/ UNICEF/UNFPA, 2000. 
5. Annual report. EPI coverage. Lahore, Punjab, Directorate General of Health Services, 2001 and 2002.

6. Afridi NK et al. Coverage and factors associated with tetanus toxoid vaccination status among females of reproductive age in Peshawar. Journal of the College of Physicians and Surgeons of Pakistan, 2005, 15(7):391-5.

7. District population profile: Punjab. Islamabad, Pakistan, Multi-donor Support Unit, March 2002.

8. Expanded Programme on Immunization: coverage evaluation survey 2003. Lahore, Provincial Health Department, Government of the Punjab, UNICEF/Contech International Health Consultants, 2003.

9. De Francisco A, Chakraborty J. Maternal recall of tetanus toxoid vaccination.
Annals of tropical paediatrics, 1996, 16(1):49-54.

10. Mara I et al. Tetanus immunization in pregnant women: evaluation of maternal tetanus vaccination status and factors affecting rate of vaccination coverage. Public health, 2001, 115(5):359-64.

11. Roosihermiatie B, Nishiyama M, Nakae K. Factors associated with TT (tetanus toxoid) immunization among pregnant women in Saparua, Maluku, Indonesia. Southeast Asian journal of tropical medicine and public health, 2000, 31(1):91-5.

12. Thind A. Determinants of tetanus toxoid immunization in pregnancy in rural Bihar. Tropical doctor, 2005, 35(2):75-7

\section{Tetanus vaccine: WHO position paper}

In countries with effective immunization programmes and good standards of hygiene, maternal and neonatal tetanus (MNT) has been largely eliminated (< 1 case per 1000 live births at the district level). A remarkable reduction in the number of MNT cases has also been achieved in many developing countries. Monetheless, in 2004, an estimated 40 million pregnant women were still in need of immunization against birth-associated tetanus, and about 27 million children did not complete their primary tetanus immunization series.

The goals of tetanus control are primarily (i) to eliminate MNT globally; and (ii) to achieve and sustain high coverage of 3 doses of DTP and of appropriate booster doses in order to prevent tetanus in all age groups. 